ORIGINAL ARTICLE

\title{
New insights into the biodegradation of thiodiglycol, the hydrolysis product of Yperite (sulfur mustard gas)
}

\author{
E. Dell'Amico ${ }^{1}$, S. Bernasconi ${ }^{2}$, L. Cavalca ${ }^{1}$, C. Magni ${ }^{3}$, B. Prinsi ${ }^{4}$ and V. Andreoni ${ }^{1}$ \\ 1 Department of Food Science and Microbiology, State University of Milan, Milan, Italy \\ 2 Department of Organic and Industrial Chemistry, State University of Milan, Milan, Italy \\ 3 Department of Agri-Food Molecular Sciences, State University of Milan, Milan, Italy \\ 4 Department of Crop Production, State University of Milan, Milan, Italy
}

\section{Keywords}

biodegradation, metabolites, methanol

dehydrogenase, Paracoccus, thiodiglycol.

\section{Correspondence}

Vincenza Andreoni, Department of Food

Science and Microbiology, State University of

Milan, Via Celoria 2, I-20133 Milan, Italy.

E-mail: vincenza.andreoni@unimi.it

2008/1296: received 25 July 2008, revised 4 September 2008 and accepted 10 September 2008

doi:10.1111/j.1365-2672.2008.04074.x

\begin{abstract}
Aims: To isolate thiodiglycol (TDG)-degrading bacteria, the mustard gas hydrolysis product, and to characterize the metabolites formed and the enzymes involved in the degradation.

Methods and Results: Two strains, identified as Achromobacter xylosoxydans G5 and Paracoccus denitrificans E4, isolated from a petroleum-contaminated soil, utilized TDG as sole carbon and sulfur source. During the degradation of TDG by strain E4 [(2-hydroxyethyl)thio] acetic acid (HETA), thiodiglycolic acid (TDGA) and bis-(2-hydroxyethyl)disulfide (BHEDS) were identified by gas chromatography-mass spectrometry analysis, while HETA and TDGA were identified for strain G5. Two-dimensional isoelectric focussing-gel electrophoresis (2-D IEF/SDS-PAGE) maps of protein extracts of $P$. denitrificans E4 grown on TDG showed a spot identified as a methanol dehydrogenase. Increased expression of a putative iscS gene, involved in sulfur assimilation, was observed in TDG-grown cells of A. xylosoxydans G5.

Conclusions: TDG degradation by $P$. denitrificans E4 occurred through two pathways: one involved cleavage of the C-S bond of HETA, yielding BHEDS and the other, oxidation of the alcoholic groups of TDG, yielding TDGA. The cleavage of the C-S bond of TDGA gave mercaptoacetic acid, further oxidized to acetate and sulfate.

Significance and Impact of the Study: Increased knowledge of TDG-degrading bacteria and the possibility of using them in a tailored-two-stage mustard gas destruction process.
\end{abstract}

\section{Introduction}

Thiodiglycol (TDG), namely bis-(2-hydroxyethyl) sulfide, is a chemical used in both private industry (textile dyeing, printing solvents and other industrial applications) and the military sector. TDG is the precursor and the main hydrolysis product of sulfur mustard gas or Yperite, i.e. bis-(2-chloroethyl) sulfide, the most produced and stored chemical warfare agent. Yperite is markedly cytotoxic and is also a carcinogenic and mutagenic alkylating agent. Furthermore, it is a vesicant that is slightly soluble in water and, under alkaline conditions, hydrolysable, with the formation of the un-chlorinated water-soluble compound, TDG (Munro et al. 1999). Since 1999, the destruction of Yperite has mainly been through incineration or neutralization, both very expensive processes, and, compared with these conventional processes, bioremediation offers a very advantageous alternative method because of its minimal environmental impact and its cost effectiveness. Biodegradation of mustard gas has not been achieved under laboratory conditions probably because of its toxicity to micro-organisms (Munro et al. 1999).

A two-step process for the destruction of mustard gas has already been conceived and developed: the first step 
lies in the chemical hydrolysis of the gas (Harvey et al. 1998) or the chemical treatment of mustard-lewisite mixtures (Boronin et al. 2000), and the second step the biodegradation of the detoxification product, namely TDG. Although TDG has a lower toxicity, it has to be destroyed and not left to accumulate in the environment, as specified by the Chemical Weapons Convention of the Organization for the Prohibition of Chemical Weapons (U.S. Arms Control and Disarmament Agency 1993).

In this context, the biodegradation of mustard gas can be closely related to the utilization of TDG by microorganisms. Some organisms such as Candida rugosa (Kawashima 1995) and Alcaligenes xylosoxydans PGH10 (Garcia-Ruiz et al. 2002) transform TDG through oxidation. Other bacteria, such as Alc. xylosoxydans ssp. denitrificans strain TD2 (Ermakova et al. 2002), Pseudomonas sp. 8-2 (Medvedeva et al. 1998), Alc. xylosoxydans ssp. xylosoxydans strains SH42 (Harvey and DeFrank 1993) and SH91 (Kim et al. 1997; Lee et al. 2000) use TDG as sole carbon source. The utilization of TDG by Alc. xylosoxydans SH91 gave [(2-hydroxyethyl)thio]acetic acid (HETA) and thiodiglycolic acid (TDGA) as intermediate products, which were further completely degraded (Lee et al. 1997, 2000). Rhodococcus rhodochrous IGTS8 cultures are instead able to use TDG as the sulfur source for growth (Kilbane and Jakowski 1996).

Recently, a Pseudomonas sp. tolerant to the organochlorine substances in mustard gas hydrolysate has been found to be capable of utilizing mustard gas hydrolysis products and of degrading TDG (Medvedeva et al. 2007).

The present paper reports an investigation aimed at studying the TDG catabolism pathway in two new bacterial isolates, performed by analysing: (i) the intermediates formed in the course of TDG degradation in the absence and presence of 4-methyl pyrazole, an alcohol dehydrogenase inhibitor; (ii) PCR amplifications of genes coding for enzymes potentially involved in TDG catabolism and in $S$ assimilation; (iii) 2D protein profiles of strains grown on TDG and on succinate. The identification of metabolites led us to the determination of two possible metabolic pathways for TDG degradation by Paracoccus denitrificans strain E4.

\section{Materials and methods}

\section{Chemicals}

TDG, 2,2'-sulfonyldiethanol (DGSO $;$; 60-65\% by wt. aqueous solution), diethylene glycol, ethylene glycol, methanol, ethanol, 1-butanol, hexane, dodecane and hexadecane were purchased from Sigma-Aldrich Chemie (Steinheim, Germany); TDGA, diethyl sulfide, 2-ethoxyethanol, 2-mercaptoethanol (MeET), mercaptoacetic acid
(MAA), dimethyl sulfoxide (DMSO) and sulfoacetic acid (SAA) from Fluka Chemie (Buch, Switzerland). Ethyl 2-hydroxyethyl sulfide was purchased from Thermo Fisher Scientific (Geel, Belgium). All other chemicals were reagent grade.

\section{Synthesis of $2,2^{\prime}$-sulfenyldiethanol}

2,2'-Sulfenyldiethanol (DGSO), a possible metabolite of TDG biodegradation, was synthesized as follows: an aliquot of $1.65 \mathrm{ml}$ of $\mathrm{H}_{2} \mathrm{O}_{2}$ was slowly added to a mixture of $1.5 \mathrm{ml}$ TDG and $7.5 \mathrm{ml}$ acetone, maintained at $3-4^{\circ} \mathrm{C}$ in an ice bath. The mixture was stirred overnight on ice, then the liquid phase was decanted and the formed crystals were purified by precipitation with acetone from a warmed aqueous solution. The DGSO yield was $0.33 \mathrm{~g}$. Analytical data of DGSO are reported in Table 1.

Enrichment, isolation, identification and characterization of TDG-degrading strains

Soil samples taken from a petroleum-contaminated area were used to enrich the bacterial strains capable of utilizing TDG as sole $\mathrm{C}$ and $\mathrm{S}$ source. Three grams of soil were mixed with $27 \mathrm{ml}$ of sterile minimal elemental (ME) medium supplemented with $4.8 \mathrm{mmol} \mathrm{l}^{-1}$ of TDG. Cycloheximide $\left(0 \cdot 1 \mathrm{~g} \mathrm{l}^{-1}\right)$ was added to the medium to inhibit the growth of eukaryotic cells. The cultures were shaken at $150 \mathrm{rev} \mathrm{min}^{-1}$ at $30^{\circ} \mathrm{C}$ for 7 days. The components of ME were as follows $\left(\mathrm{g} \mathrm{l}^{-1}\right)$ : $\mathrm{NH}_{4} \mathrm{Cl}, 2 \cdot 0 ; \mathrm{MgCl}_{2} \cdot 6 \mathrm{H}_{2} \mathrm{O}, 0 \cdot 2$; $\mathrm{K}_{2} \mathrm{HPO}_{4}, 4 \cdot 0 ; \mathrm{NaH}_{2} \mathrm{PO}_{4}, 4 \cdot 0 ; \mathrm{CaCl}_{2} \cdot 2 \mathrm{H}_{2} \mathrm{O}, 0 \cdot 001$ and $\mathrm{FeCl}_{3} \cdot 6 \mathrm{H}_{2} \mathrm{O}, 0 \cdot 001$. The medium was supplemented with microelements in the following concentrations $\left(\mathrm{mg} \mathrm{l}^{-1}\right)$ : $\mathrm{FeCl}_{2} \cdot 4 \mathrm{H}_{2} \mathrm{O}, 1 \cdot 5 ; \mathrm{CoCl}_{2} \cdot 6 \mathrm{H}_{2} \mathrm{O}, 0 \cdot 19 ; \mathrm{CuCl}_{2} \cdot 2 \mathrm{H}_{2} \mathrm{O}, 0 \cdot 017 ;$ $\mathrm{H}_{3} \mathrm{BO}_{3}, 0.06 ; \mathrm{ZnCl}_{2}, 0 \cdot 07 ; \mathrm{MnCl}_{2} 4 \mathrm{H}_{2} \mathrm{O}, 0 \cdot 1 ; \mathrm{Na}_{2} \mathrm{MoO}_{4}$. $2 \mathrm{H}_{2} \mathrm{O}, 0 \cdot 036$; and $\mathrm{NiCl}_{2} \cdot 6 \mathrm{H}_{2} \mathrm{O}, 0 \cdot 024$. The final $\mathrm{pH}$ of $\mathrm{ME}$ was adjusted to 7 with a $1-\mathrm{mol}^{-1} \mathrm{NaOH}$ and the medium was autoclaved at $121^{\circ} \mathrm{C}$ for $20 \mathrm{~min}$. When necessary, a solution of $6 \mathrm{mmol} \mathrm{l}{ }^{-1} \mathrm{Na}_{2} \mathrm{SO}_{4}$ was added as sulfur source.

The culture was adapted to utilize TDG through seven subsequent passages by re-inoculation of 1 -ml cell suspensions in $20 \mathrm{ml}$ of fresh $\mathrm{ME}$ medium. The enriched culture was then serially diluted and seeded on 10-fold diluted Tryptic Soy agar (TSA 0·1×; Difco, Detroit, MI, USA). After 8 days of incubation at $30^{\circ} \mathrm{C}$, the colonies that appeared on the plates were isolated and tested for capability to grow on TDG.

The growth of the isolates on TDG and on TDGrelated or -unrelated substrates was tested in 100-ml flasks containing $20 \mathrm{ml}$ of $\mathrm{ME}$ with the appropriate compound added. The flasks were shaken at 
Table 1 Analytical data of TDG and related metabolites

\begin{tabular}{|c|c|c|c|c|}
\hline & $G C^{*}(R t)$ & HPLC (Rt) & ${ }^{1} \mathrm{H}-\mathrm{NMR}\left(\mathrm{DMSO}-\mathrm{d}_{6}\right)$ & GC-MS or MS (EI) $\dagger$ \\
\hline TDG & $7 \cdot 02$ & $4 \cdot 20$ & $\begin{array}{l}4 \cdot 75(\mathrm{t}, 2 \mathrm{H}, 2 \mathrm{OH}) \\
3 \cdot 50\left(\mathrm{q}, 4 \mathrm{H}, 2 \mathrm{CH}_{2}-\mathrm{O}-\right) \\
2 \cdot 58\left(\mathrm{t}, 4 \mathrm{H}, 2 \mathrm{CH}_{2}-\mathrm{S}-\right)\end{array}$ & $\begin{array}{l}266(0 \%), 251(7 \%), 191(7 \%), 176(30 \%), 161(15 \%), 130(20 \%), \\
117(32 \%), 116(90 \%), 103(65 \%), 101(25 \%), 87(25 \%) \\
75(42 \%), 73(100 \%)\end{array}$ \\
\hline ОТО & $2 \cdot 29$ & nd & $\begin{array}{l}4 \cdot 69(\mathrm{~m}, 1 \mathrm{H}, \mathrm{O}-\mathrm{CH}-\mathrm{O}) \\
4 \cdot 17 \text { and } 3 \cdot 69 \\
(2 \mathrm{~m}, 2 \mathrm{H}, \mathrm{S}-\mathrm{C}-\mathrm{CH} 2-\mathrm{O}) \\
2 \cdot 67-2 \cdot 45 \\
(\mathrm{~m}, 3 \mathrm{H}, \mathrm{O}-\mathrm{C}-\mathrm{CH}-\mathrm{S}-\mathrm{CH} 2) \\
2 \cdot 32(\mathrm{bd}, 1 \mathrm{H}, \mathrm{O}-\mathrm{C}-\mathrm{CH}-\mathrm{S})\end{array}$ & $\begin{array}{l}192(32 \%), 170(20 \%), 133(17 \%), 119(85 \%), 103(73 \%), 79(98 \%), \\
77(75 \%), 73(100 \%)\end{array}$ \\
\hline HETA & $7 \cdot 59$ & $3 \cdot 76$ & $\begin{array}{l}3 \cdot 54\left(\mathrm{t}, 2 \mathrm{H}, \mathrm{CH}_{2}-\mathrm{O}-\right) \\
3 \cdot 24\left(\mathrm{~s}, 2 \mathrm{H}, \mathrm{S}-\mathrm{CH}_{2}-\mathrm{CO}\right) \\
2 \cdot 68\left(\mathrm{t}, 2 \mathrm{H}, \mathrm{CH}_{2}-\mathrm{S}-\right)\end{array}$ & $\begin{array}{l}280(10 \%), 265(15 \%), 204(7 \%), 190(52 \%), 133(13 \%), 117(18 \%), \\
103(25 \%), 89(9 \%), 73(100 \%)\end{array}$ \\
\hline TDGA & $8 \cdot 33$ & $3 \cdot 56$ & $3 \cdot 35\left(\mathrm{~s},-\mathrm{CH}_{2}-\mathrm{S}-\right)$ & $\begin{array}{l}294(10 \%), 279(7 \%), 204(55 \%), 117(12 \%), 87(7 \%), 79(2 \%) \\
75(45 \%), 73(100 \%)\end{array}$ \\
\hline BHEDS & $9 \cdot 46$ & $3 \cdot 68$ & $\begin{array}{l}4 \cdot 85(\mathrm{~m}, 2 \mathrm{H}, 2 \mathrm{OH}) \\
3 \cdot 62\left(\mathrm{t}, 4 \mathrm{H}, 2 \mathrm{CH}_{2}-\mathrm{O}-\right) \\
2 \cdot 79\left(\mathrm{t}, 4 \mathrm{H}, 2 \mathrm{CH}_{2}-\mathrm{S}-\right)\end{array}$ & $\begin{array}{l}298(30 \%), 182(11 \%), 154(8 \%), 133(28 \%), 117(56 \%), 107(48 \%), \\
103(28 \%), 92(14 \%), 73(100 \%)\end{array}$ \\
\hline DGSO & $9 \cdot 69$ & $3 \cdot 75$ & $\begin{array}{l}4.95(\mathrm{t}, 2 \mathrm{H}, 2 \mathrm{OH}) \\
3 \cdot 80\left(\mathrm{bq}, 4 \mathrm{H}, 2 \mathrm{CH}_{2}-\mathrm{O}-\right) \\
2 \cdot 90\left(\mathrm{~m}, 4 \mathrm{H}, 2 \mathrm{CH}_{2}-\mathrm{S}-\right)\end{array}$ & $\begin{array}{l}\text { El: } \\
138(7 \%) \\
94(65 \%), 76(100 \%), 63(50 \%) \\
\text { GC-MS: } \\
283(3 \%) \\
267(45 \%), 238(18 \%), 166(62 \%), 135(30 \%), 117(100 \%), 103(25 \%), \\
87(7 \%), 73(76 \%), 59(10 \%)\end{array}$ \\
\hline $\mathrm{DGSO}_{2}$ & $9 \cdot 87$ & $3 \cdot 62$ & $\begin{array}{l}5 \cdot 06(t, 2 \mathrm{H}, 2 \mathrm{OH}) \\
3 \cdot 80\left(\mathrm{q}, 4 \mathrm{H}, 2 \mathrm{CH}_{2}-\mathrm{O}-\right) \\
3 \cdot 26\left(\mathrm{t}, 4 \mathrm{H}, 2 \mathrm{CH}_{2}-\mathrm{S}-\right)\end{array}$ & $\begin{array}{l}298(0 \%) \\
283(82 \%), 239(12 \%), 133(7 \%), 117(53 \%), 101(22 \%), 88(12 \%), \\
75(58 \%), 73(100 \%)\end{array}$ \\
\hline
\end{tabular}

*The reported retention times (Rt) are relative to trimethylsilyl derivatives of the indicated products.

$\dagger$ All the reported GC-MS data are relative to trimethylsilyl derivatives. For DGSO are reported also the data for the compound before derivatisation (El).

$150 \mathrm{rev} \mathrm{min}^{-1}$ at $30^{\circ} \mathrm{C}$. All growth experiments were done at least twice.

TDG, diethylene glycol, ethylene glycol, diethyl sulfide, ethyl 2-hydroxyethyl sulfide, 2-ethoxyethanol, DGSO, $\mathrm{DGSO}_{2}, \mathrm{MeET}, \mathrm{MAA}, \mathrm{SAA}, \mathrm{DMSO}$, methanol, ethanol 1-butanol, hexane, dodecane and hexadecane were separately added to the cultures; TDGA sodium salt and succinate were supplied as aqueous solutions. All compounds and solutions were added to the medium after filter sterilization with a $0 \cdot 45-\mu \mathrm{m}$-pore-size membrane filter.

G5 and E4 strains were identified by phylogenetic analyses (neighbour-joining method). Overnight cell suspensions grown on $\mathrm{LB}$ medium $(100 \mu \mathrm{l} \mathrm{OD} 600=2 \cdot 0)$ were centrifuged at $13000 \mathrm{~g}$ for $7 \mathrm{~min}$ and the pellet suspended in $100 \mu \mathrm{l}$ of sterile MilliQ water, $100 \mu \mathrm{l}$ of $10 \mathrm{mmol} \mathrm{l}^{-1}$ Tris- $\mathrm{HCl}$ buffer $(\mathrm{pH} 8 \cdot 0$ ) and $13 \mu \mathrm{l}$ of Proteinase K $\left(1 \mathrm{mg} \mathrm{ml}^{-1}\right)$. The mix was incubated for $2 \mathrm{~h}$ at $55^{\circ} \mathrm{C}$, then boiled for $10 \mathrm{~min}$ and centrifuged at $13000 \mathrm{~g}$ for $5 \mathrm{~min}$. The DNA-containing supernatant was withdrawn and put into sterile microtubes. TDG-degrading strains were identified on the basis of sequence analysis of near-complete
$16 \mathrm{~S}$ rRNA gene, using eubacterial universal primers P27f and P1495r referred to an Escherichia coli nucleotide sequence of 16S rRNA gene (Weisburg et al. 1991).

\section{TDG degradation experiments}

TDG degradation experiments were carried out in triplicate in $500 \mathrm{ml}$ bottles, each containing $90 \mathrm{ml}$ of ME medium. TDG was added to the bottles at the required concentration. Each bottle was inoculated with $10 \mathrm{ml}$ of the cell suspension grown on TDG, then closed with a butyl rubber stopper and incubated under shaking at $150 \mathrm{rev} \mathrm{min}^{-1}$ at $30^{\circ} \mathrm{C}$; samples were taken at intervals to determine cell density, TDG consumption and metabolite formation.

To test the involvement of an alcohol dehydrogenase activity in the initial breakdown on TDG, the strains were grown in $100 \mathrm{ml}$ bottles containing $20 \mathrm{ml}$ of ME medium containing $10 \mathrm{mmol} \mathrm{l}^{-1}$ of TDG in both the presence and absence of $1 \mathrm{mmol} \mathrm{l}^{-1}$ 4-methylpyrazole (Sigma-Aldrich), an inhibitor of alcohol dehydrogenase (Brimfield et al. 1998). Cell density was measured at appropriate intervals, 
while the metabolite concentrations in the culture broth were measured only at the end of the experiments.

\section{Analytical procedures and metabolite extraction}

Growth was monitored by recording the increase in $\mathrm{OD}_{600 \mathrm{~nm}}$ with a model UV-1700 spectrophotometer (Beckman model DU 640). TDG, HETA and TDGA concentrations were monitored by HPLC chromatograph (Merck-Hitachi L6200 Intelligent pump with L4000 UV detector; Japan Servo Co., Japan) equipped with a column Supelco C18 Discovery (25-cm long). A mixture of wateracetonitrile $(60: 40)$ was the mobile phase and the flow rate was $0.7 \mathrm{ml} \mathrm{min}{ }^{-1}$. The compounds were detected by measuring UV absorbance at $220 \mathrm{~nm}$ and their relative retention times (Rt) are reported in Table 1. The concentrations of TDG and TDGA were calculated using standards of known concentrations; that of HETA using samples extracted from culture broths. To identify the metabolites, ${ }^{1} \mathrm{H}$-NMR analyses of the crude organic extracts were performed with a Bruker Ultrashield 400 using DMSO- $\mathrm{d}_{6}$ as solvent. The values of the signals are reported in Table 1. After derivatization of crude organic extracts with bis(trimethylsilyl)trifluoroacetamide, gas chromatography (GC) and gas chromatography-mass spectrometry (GCMS) analyses were performed. The GC analyses were performed using a DANI 1000 gas-chromatograph equipped with an FID detector (hydrogen 0.9 bar, air 1.0 bar and nitrogen $1.0 \mathrm{bar}$ ) and a fused silica capillary column WCOT-CP-Sil 8 CB Chrompack $(25 \mathrm{~m} \times 0.32 \mathrm{~mm}$ i.d.), carrier helium $(0.8 \mathrm{bar})$, injector temperature $200^{\circ} \mathrm{C}$, detector temperature $250^{\circ} \mathrm{C}$, oven temperature $90^{\circ} \mathrm{C}(2 \mathrm{~min})$, temperature increase $10^{\circ} \mathrm{C} \mathrm{min}{ }^{-1}$, final isotherm $250^{\circ} \mathrm{C}$, injection volume $2 \mu \mathrm{l}$. All chromatograms and data were generated and processed by DANI Data Station ver. 1.7 software (Dani Instruments, Cologno Monzese, Italy). The same column and chromatographic conditions were used for GC-MS, and mass spectra were recorded on a VG 7070 EQ instrument. For the extraction of the metabolites the culture broth, after $\mathrm{pH}$ control, was treated with solid $\mathrm{NaCl}$ until saturation, and then filtered into a separatory funnel. In the presence of acidic $\mathrm{pH}$, the broth was extracted by ethyl acetate ( 3 times with a volume of ethyl acetate as $3 / 5$ of the volume of aqueous solution) and the organic layers collected, dried with solid $\mathrm{Na}_{2} \mathrm{SO}_{4}$ and filtered. The organic solvent was eliminated by evaporation under reduced pressure. In the presence of neutral $\mathrm{pH}$, the broth was extracted as described above and subsequently acidified by adding a 6-mol $\mathrm{l}^{-1} \mathrm{HCl}$ solution to give a $\mathrm{pH}$ of $2-3$ and then a second extraction was performed. The obtained crude extracts (from the neutral and acidic aqueous phases) were dissolved separately in 5 -ml ethyl acetate; $4 \mathrm{ml}$ of the solution was dried and submitted to ${ }^{1} \mathrm{H}$-NMR analysis and $1 \mathrm{ml}$ was transferred drop by drop into a glass vial $(0 \cdot 1 \mathrm{ml})$ under dry nitrogen stream to evaporate the solvent and prepare the sample for the silylation procedure. To the raw material, $100 \mu \mathrm{l}$ of pyridine and $100 \mu \mathrm{l}$ of bis-(trimethylsilyl)trifluoroacetamide were added and the mixture maintained at $40^{\circ} \mathrm{C}$ for $30 \mathrm{~min}$, after which it was ready for gas-chromatographic or gas-mass analyses. The Rt values and the spectroscopic properties of TDG and the related metabolites detected in the culture broths are shown in Table 1.

To determine the presence of any sulfates, aliquots of the culture broth $(0.5 \mathrm{ml})$, filtered through a $0 \cdot 2-\mu \mathrm{m}$ pore-size membrane filter, were acidified with $6-\mathrm{mol} \mathrm{l}^{-1}$ $\mathrm{HCl}\left(\mathrm{pH}\right.$ 2) and $0.5 \mathrm{ml}$ of a $5-\mathrm{mol} \mathrm{l}^{-1} \mathrm{BaCl}_{2}$ solution were added to the sample. The precipitation of $\mathrm{BaSO}_{4}$ revealed sulfate formation.

\section{Molecular methods}

Genes potentially involved in TDG degradation were searched for by PCR amplification of the following gene fragments: $t b m A$ for toluene 2-monoxygenase, responsible for growth on ether and thioether compounds by Burkholderia cepacia G4/PR1 (Hur et al. 1997); bdhA for butanol dehydrogenase in Aeromonas hydrophila JMP636 (AF388671; Schmidt and Pemberton, unpublished data). An iscS gene for cysteine desulfurase involved in sulfur assimilation process was also searched (Mihara and Esaki 2002). Table 2 shows the primers used. Primers for iscS were designed on the consensus region of Pseudomonas fluorescens Pf-5 (CP000076) and Burkholderia pseudomallei K96243 (BX571965), Ralstonia pickettii 12J (CP001068) and Bradyrhizobium sp. BTAil (NC009485), and primers for $b d h A$ on the consensus region of Aer. hydrophila JMP636 (AF388671), Burkholderia pseudomallei 1655 (DS981341) and of Rhizobium leguminosarum bv. viciae

Table 2 Oligonucleotide primers used for PCR amplification of genes potentially involved in TDG degradation and in the S assimilation pathway

\begin{tabular}{lllll}
\hline Gene & Forward primer (5'-3') & Reverse primer (5'-3') & $\begin{array}{l}\text { Theoretical PCR } \\
\text { product size (bp) }\end{array}$ & References \\
\hline tbma & AAGACCTATCCSGARTACGT & GGCTGGATCWGRCCTGCSAGGAA & 1200 & Cavalca et al. (2004) \\
bdhA & GTCCCTATCTTGTCAAA & CGCCCAGGCTCGCGACCA & 710 & This work \\
iscS & AAGCGGATCGAGCTGTGMGC & GYGAAGGCTTCARGTGACC & 720 & This work \\
\hline
\end{tabular}

$S$ is for $C+G ; R$, for $A+G ; W$, for $A+T, M$, for $A+C, Y$, for $C+T$. 
3841 (NC008380). The PCR mix consisted of deoxynucleotide triphosphates at $200 \mu \mathrm{mol} \mathrm{l}{ }^{-1}$ each, $0 \cdot 30 \mu \mathrm{mol} \mathrm{l}^{-1}$ each primer, $2 \cdot 0 \mathrm{mmol}^{-1} \mathrm{MgCl}_{2}, 1 \times$ PCR buffer and $1 \mathrm{U}$ of Taq DNA polymerase (Invitrogen, Paisley, UK) in a total volume of $50 \mu \mathrm{l}$. The annealing temperatures were $55^{\circ} \mathrm{C}$ for $t b m A, 51^{\circ} \mathrm{C}$ for $b d h A$ and $52^{\circ} \mathrm{C}$ for iscS.

For the semi-quantitative transcriptional analysis, a reverse transcriptase (RT)-PCR approach was taken. DNAse-treated total RNAs were reverse transcribed to first-strand cDNA using Stratascript Reverse Transcriptase (Stratagene, La Jolla, CA, USA) according to the manufacturer's instructions; cDNA aliquots from the RT reactions were used for the amplification of iscS gene with Taq DNA Polymerase (Invitrogen, UK), using the primers for iscS listed in Table 2. The PCR products were separated on $2 \%$ agarose gels along with O'gene Ruler 1-kb ladder (Fermentas, Burlington, ON, Canada). As positive control, genomic DNA from the same strain was used as template. As negative control, not-reverse transcribed DNAse-treated RNA was used as template in order to avoid false-positive results.

Total RNA was extracted from Achromobacter xylosoxydans G5 cultures after 5-day growth in ME medium supplemented either with TDG $\left(6 \mathrm{mmol} \mathrm{l}^{-1}\right)$ or succinate and $\mathrm{Na}_{2} \mathrm{SO}_{4}\left(6 \mathrm{mmol} \mathrm{l}^{-1}\right.$ each $)$. Samples $\left(10^{10}\right.$ cells $)$ were spun down (8000 $\mathrm{g}$ for $15 \mathrm{~min}$ ), the cell pellets were suspended in $3 \cdot 25-\mathrm{ml}$ lysing buffer $\left(80 \mathrm{mmol}^{-1}\right.$ Tris- $\mathrm{HCl}$ buffer $\mathrm{pH}$ $7 \cdot 6$ containing $800 \mathrm{mmol} \mathrm{l}^{-1} \mathrm{NaCl}$ and $8 \mathrm{mmol} \mathrm{l}^{-1}$ EDTA) and digested for $1 \mathrm{~h}$ at $50^{\circ} \mathrm{C}$ with $1 \mathrm{mg}$ proteinase K. RNA was further extracted with phenol: chloroform: isoamyl alcohol (25:24:1) and chloroform: isoamyl alcohol (24: 1). RNA was recovered after precipitation with ethanol and treated with RNAse-free DNAse I (GE Healthcare, Stockholm, Sweden).

\section{2-D IEF/SDS-PAGE and image analysis}

G5 and E4 strains were grown separately in $100 \mathrm{ml} \mathrm{ME}$ medium containing either succinate and $\mathrm{Na}_{2} \mathrm{SO}_{4}$ $\left(6 \mathrm{mmol} \mathrm{l}^{-1}\right.$ each) or TDG $\left(6 \mathrm{mmol}^{-1}\right)$. Cells were harvested by centrifugation ( $15 \mathrm{~min}$ at $10000 \mathrm{~g}$ at $5^{\circ} \mathrm{C}$ ) after 3 days of growth, washed twice with $50 \mathrm{mmol} \mathrm{l}^{-1}$ Tris$\mathrm{HCl}$ buffer ( $\mathrm{pH} 7 \cdot 5$ ) containing $0.3 \mathrm{~mol} \mathrm{l}^{-1} \mathrm{NaCl}$. Each cell pellet was suspended in $10 \mathrm{ml}$ of lysis buffer [7 $\mathrm{mol} \mathrm{l}^{-1}$ urea, $2 \mathrm{~mol} \mathrm{l}^{-1}$ thiourea, 2\% CHAPS, $65 \mathrm{mmol} \mathrm{l}^{-1}$ 1,4-dithiothreitol (DTT)] and disrupted by sonication (Sonifier 250; Branson, Marchan, Ontario, Canada). The resultant lysate was centrifuged at $13000 \mathrm{~g}$ for $10 \mathrm{~min}$ at $4^{\circ} \mathrm{C}$, and the supernatant was collected. The protein concentration was determined using 2D Quant Kit (Amersham Bioscience).

Isoelectric focussing was performed on $7 \mathrm{~cm}, \mathrm{pH} 3-10$ linear IPG strips (GE Healthcare, Milan, Italy). The strips were rehydrated overnight in a solution consisting of $7 \mathrm{~mol} \mathrm{l}^{-1}$ urea, $2 \mathrm{~mol} \mathrm{l}^{-1}$ thiourea, 2\% CHAPS, $65 \mathrm{mmol} \mathrm{l}^{-1}$ 1,4-dithiothreitol, 2\% IPG buffer $\mathrm{pH}$ 3-10 (GE Healthcare, Milan, Italy) containing $50 \mu \mathrm{g}$ of the protein sample. Strips were focussed at $6500 \mathrm{~V}$-h, with a maximum of $3000 \mathrm{~V}$, at $20^{\circ} \mathrm{C}$ using the Multiphor II electrophoresis unit (Amersham Biosciences, Milan, Italy). Prior to the second dimension, the strips were incubated in equilibration buffer $\left(375 \mathrm{mmol}^{-1}\right.$ Tris- $\mathrm{HCl}, \mathrm{pH} 8 \cdot 8$, $6 \mathrm{~mol} \mathrm{l}^{-1}$ urea, 2\% SDS, 20\% glycerol) with $65 \mathrm{mmol} \mathrm{l}^{-1}$ DTT for $15 \mathrm{~min}$, then with $243 \mathrm{mmol} \mathrm{l}^{-1}$ iodoacetamide in the same buffer without DTT for $10 \mathrm{~min}$. The separation was performed in 12\% SDS-PAGE gels using a mini-PROTEAN III cell (Bio-Rad, Milan, Italy). Three gel replicates were produced for each sample. The gels were stained with Coomassie Brilliant Blue (CBB), scanned in an Epson Expression 1680 Pro Scanner and analysed with ImAgemaster 2-D Platinum Software (GE Healthcare, Milan, Italy).

\section{Protein in-gel digestion and liquid chromatography} electrospray ionization tandem mass spectrometry

Protein spot was excised from CBB stained 2-DE gel and in-gel digested as described by Magni et al. (2007).

The obtained sample was analysed using a Finnigan LCQ Deca XP MAX IT mass spectrometer equipped with a Finnigan Surveyor (MS Pump Plus) HPLC system (Thermo Fisher Scientific). Chromatography separations were conducted on a BioBasic C18 column (180 $\mu$ m i.d., 150-mm long, 5- $\mu \mathrm{m}$ particle size), using a linear gradient from $5 \%$ to $80 \%$ solvent B [solvent A: $0 \cdot 05 \%(\mathrm{v} / \mathrm{v})$ formic acid; solvent B: ACN containing $0 \cdot 05 \%(\mathrm{v} / \mathrm{v})$ formic acid] with a flow of $2 \cdot 5 \mu \mathrm{l} \mathrm{min}{ }^{-1}$. The capillary temperature and the spray voltage were set at $220^{\circ} \mathrm{C}$ and at $3.0 \mathrm{kV}$, respectively. For MS/MS scans, the normalized collision energy was set at 35\%. Acquisitions were performed in data-dependent MS/MS scanning mode and enabling a dynamic exclusion window of $3 \mathrm{~min}$. Protein identification was conducted by TurboSEQUEST ${ }^{\circledR}$ Bioworks Browser 3.2 (Thermo Fisher Scientific) software through correlation of uninterpreted spectra to the entries of the $P$. denitrificans protein database downloaded from the National Center for Biotechnology Information (NCBI). The software was set to allow two missed cleavages per peptide and to take into account cysteine carboxyamidomethylation and methionine oxidation. The parent ion and fragment ion mass tolerance were set to \pm 2 and $\pm 1 \mathrm{Da}$, respectively. In order to identify proteins, only peptides with Xcorr $>1.5(+1$ charge state), $>2 \cdot 0$ ( +2 charge state), $>2.5$ ( $\geq 3$ charge state $)$ and peptide probability $<1 \times 10^{-3}$ were considered. Theoretical molecular weight and $\mathrm{pI}$ of the characterized protein were 
calculated by processing sequence entry at http://www. expasy.org/tools/pi_tool.html.

\section{Sequence accession numbers}

The nucleotide sequences of the 16S rRNA genes of strains E4 and G5 were registered in GenBank/EMBL as accession numbers FM207553 and FM207511, respectively. The nucleotide sequence of putative iscS gene has been registered as accession number EU523110.

\section{Results}

Isolation, identification and growth characteristics of TDG-degrading bacteria

One enrichment culture capable of growing on $4.8 \mathrm{mmol} \mathrm{l}^{-1}$ of TDG was obtained. Thirty colonies from the plates of the culture grown on TSA $0 \cdot 1 \times$ were isolated and re-streaked on TSA $0 \cdot 1 \times$ to obtain pure cultures. Among the isolates, two strains, named E4 and G5, utilized TDG as sole $\mathrm{C}$ and $\mathrm{S}$ source.

Phylogenetic analysis based on 16S rRNA sequences indicated that the strains E4 and G5 were identified as P. denitrificans (99.1\% sequence identity to GenBank acc. num. CP000490) and A. xylosoxydans (93\% sequence identity to GenBank acc. no. AY468369), respectively.

Table 3 shows the different growth characteristics of the strains to assimilate substrates with molecular structure similar to TDG, intermediates of TDG oxidation, and other substrates as alcohol and aliphatic hydrocarbons. They grew on TDG, TDGA, ethylene glycol, ethanol and on 1-butanol, but not on ethyl 2-hydroxyethyl ether, diethylene glycol, diethyl sulfide, DGSO, $\mathrm{DGSO}_{2}$, DMSO and MeET. Paracoccus denitrificans E4 grew well on MAA and SAA, possible derivatives of TDG degradation and on methanol, but very poorly on ethyl 2-hydroxyethyl sulfide. On the contrary, G5 scarcely grew on methanol and failed to grow on MAA and SAA. In addition, the growth of G5 on TDG in the presence of MAA was inhibited and the inhibitory effect increased with increasing MAA concentration (data not shown). Finally, A. xylosoxydans G5 grew on middle long-chain alkanes. All the results indicated a strain specificity in recognizing as growth substrates only the compounds containing a sulfide bound to oxidized chains as in the TDG molecule and not to alkylic chains as in diethylsulfide.

\section{Identification of metabolites in growing cell experiments}

Figure 1 shows profiles of $\mathrm{pH}$ variation (Fig. 1a), TDG disappearance and $\mathrm{OD}_{600 \mathrm{~nm}}$ increase (Fig. 1b) of the culture broths of the isolates. During growth and TDG
Table 3 Growth of E4 and G5 strains in ME medium supplemented with various organosulfur compounds and with related compounds

\begin{tabular}{lcc}
\hline Substrate* & E4 & G5 \\
\hline Thiodiglycol (TDG) & + & + \\
Diethylene glycol & - & - \\
Diethyl sulfide & - & - \\
Ethyl 2-hydroxyethyl sulfide & \pm & - \\
Ethyl 2-hydroxyethyl ether & - & - \\
2,2'-Sulfenyldiethanol (DGSO) & - & - \\
2,2'-Sulfonyldiethanol(DGSO $)$ & - & - \\
Thiodiglycolic acid (TDGA) & + & + \\
Dimethyl sulfoxide (DMSO) & - & - \\
2-Mercaptoethanol (MeET) & - & - \\
Mercaptoacetic acid (MAA) & + & - \\
Sulfoacetic acid (SAA) & + & - \\
Methanol & + & \pm \\
Ethanol & + & + \\
Ethylene glycol & + & + \\
1-Butanol & + & + \\
Hexane & - & + \\
Dodecane & - & + \\
Hexadecane & - & + \\
\hline
\end{tabular}

*Each compound was added at a final concentration of $5 \mathrm{mmol} \mathrm{I} \mathrm{I}^{-1}$ Growth after 4 days of incubation: growth, $+\left(\mathrm{OD}_{600 \mathrm{~nm}}>0 \cdot 3\right)$; scarce growth, $\pm\left(\mathrm{OD}_{600 \mathrm{~nm}} 0 \cdot 10-0 \cdot 18\right)$; absence of growth, $-\left(\mathrm{OD}_{600 \mathrm{~nm}}<\right.$ $0.08)$.

consumption, the $\mathrm{pH}$ values of the cultures dropped from $7 \cdot 2$ to $5 \cdot 2$ for strain E4 and from $7 \cdot 0$ to $5 \cdot 0$ for strain G5 in $48 \mathrm{~h}$. The data concerning TDG degradation by $P$. denitrificans E4 are shown in Fig. 2. HETA, TDGA, i.e. the mono and diacid derivatives of TDG, and small amounts of bis-(2-hydroxyethyl)disulfide (BHEDS), which is the oxidation product of MeET were detected. At $36 \mathrm{~h}$ of incubation, HETA was the dominant metabolite and the sulfate test was negative. HETA and BHEDS disappeared at 72 and $96 \mathrm{~h}$, respectively, while TDGA was still present. The sulfate release became evident when the $\mathrm{pH}$ dropped to $5 \cdot 2$.

TDGA was the sole metabolite extracted from the cultures of A. xylosoxydans G5. At $24 \mathrm{~h}$ of incubation, there was the presence of $3 \mathrm{mmol}^{-1}$ of TDGA, which became completely degraded at $40 \mathrm{~h}$ to coincide with the sulfate release.

Growth of strains E4 and G5 and TDG oxidation were affected differently when 4-methyl pyrazole was added to the cells growing on TDG. A growth inhibitory effect of $78 \%$ and $30 \%$ for E4 and G5 was observed, respectively (Fig. 3). At the end of the incubation time $(192 \mathrm{~h})$, 1,4-oxathian-2-ol (OTO), as the main metabolite, together with traces of HETA and TDGA were detected in $P$. denitrificans $\mathrm{E} 4$ cultures. OTO was derived from the cyclization of [(2-hydroxyethyl)thio]acetic aldehyde 
(a)
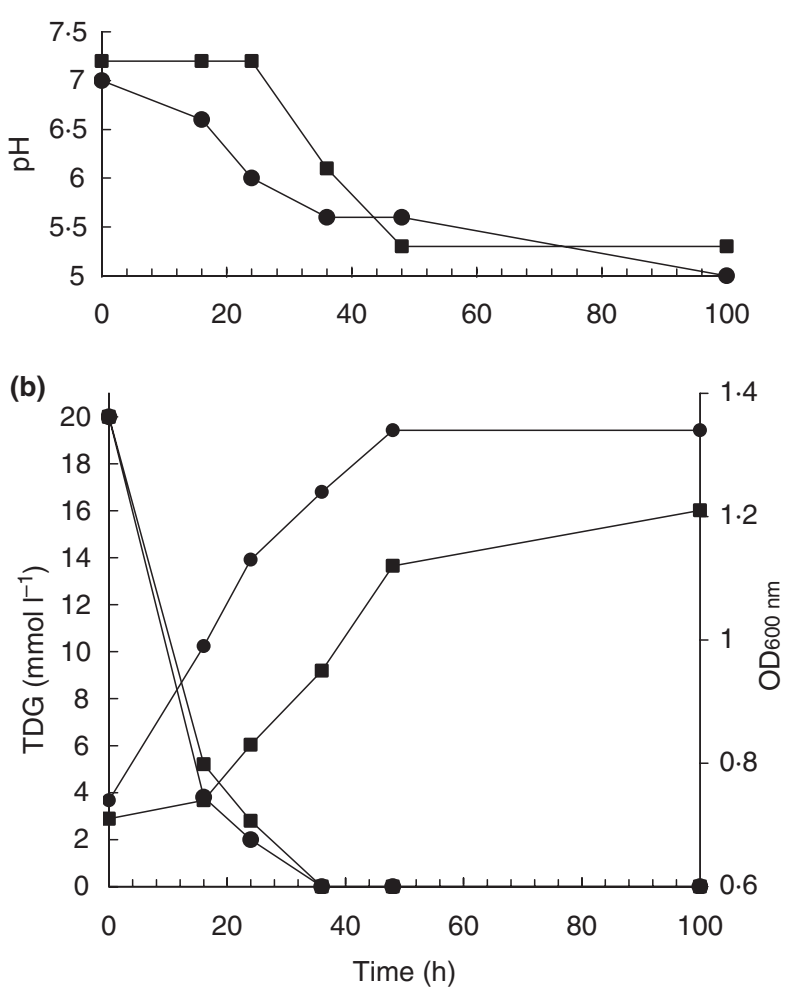

Figure 1 Utilization of $20 \mathrm{mmol} \mathrm{I}^{-1}$ of TDG as $C$ and S source by Paracoccus denitrificans E4 $(\square)$ and Achromobacter xylosoxydans G5 (0): (a) pH drop during the growth and (b) TDG consumed and increase of $\mathrm{OD}_{600 \mathrm{~nm}}$. Each value is the mean of three determinations and the SD was $<8 \%$.

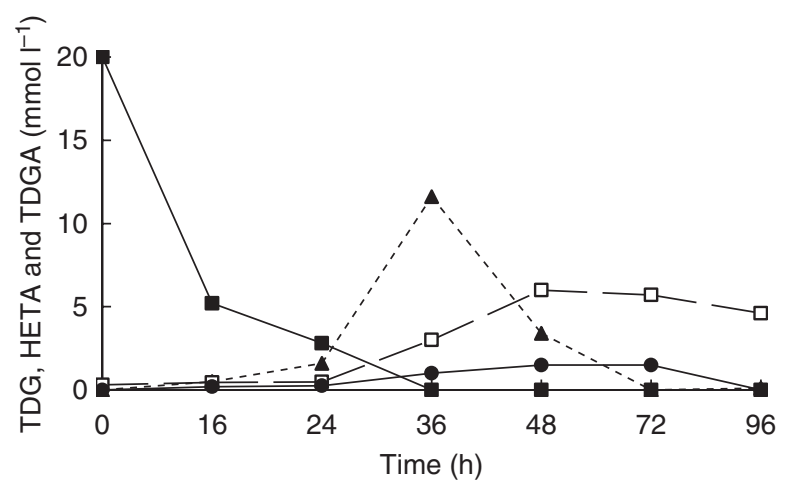

Figure 2 Time course of $20 \mathrm{mmol} \mathrm{I}^{-1}$ of TDG degradation

; HETA $(\mathbf{\Lambda})$, TDGA $(\square)$ and BHEDS $(\bullet)$ formation by Paracoccus denitrificans E4. Each value is the mean of three determinations and the SD was $<8 \%$.

(HETAL). Instead, traces of HETA were detected in the cultures of A. xylosoxydans G5. The analytical data of these metabolites are reported in Table 1.

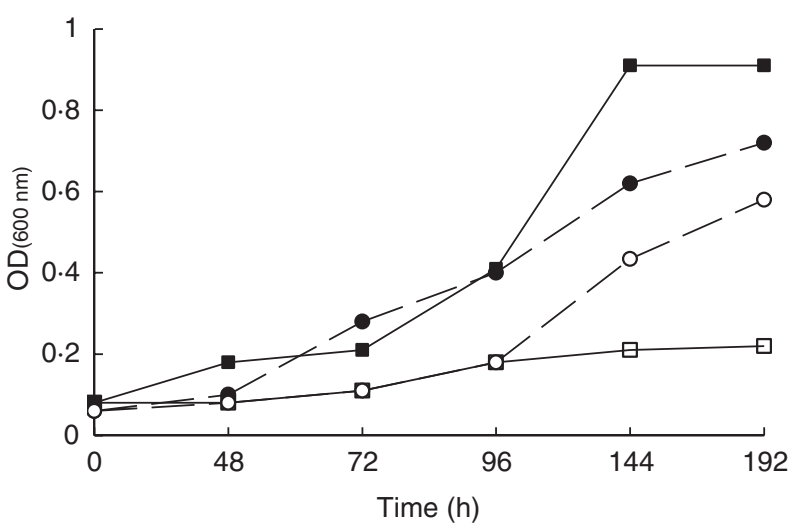

Figure 3 Growth of Paracoccus denitrificans E4 ( $\square$ ) and Achromobacter xylosoxydans $\mathrm{G} 5(\mathbf{0})$ on TDG $\left(10 \mathrm{mmol}^{-1}\right)$ in the absence (full symbol) and presence (empty symbol) of 4-methylpyrazole $\left(1 \mathrm{mmol} \mathrm{I}^{-1}\right)$. Each value is the mean of three determinations and the SD was $<10 \%$.

\section{Molecular analysis}

Molecular determinants for enzymes potentially involved in TDG degradation and sulfur assimilation were searched for by PCR amplification of gene fragments with primers for tbmA, bdhA and iscS (Table 1). None of the strains yielded amplicons related to $t b m A$ and $b d h A$. This implies that genes with different nucleotide sequence composition than the known $t b m A$ and $b d h A$ genes may be present in strains E4 and G5, or alternately these genes may be absent. However, a fragment of $720 \mathrm{bp}$ was amplified with primers for iscS in A. xylosoxydans G5 grown on TDG, in agreement with the expected size value. The iscS nucleotide sequence of A. xylosoxydans G5 revealed a similarity of $94 \%$ to part of iscS gene of Bordetella parapertussis 12822 (GenBank acc. no. BX640429). The deduced aminoacidic sequence showed a similarity of $78 \%$ with the cysteine desulfurase IscS of Pseudomonas aeruginosa PAO1 (Protein acc. no. Q9HXI8).

To determine whether the iscS gene was actually transcribed in response to TDG, transcriptional analysis was performed on total RNA isolated from TDG-grown and succinate-grown cells of A. xylosoxydans G5 (Fig. 4). With the use of a primer for iscS, an expected fragment of 720 bp was amplified from the total RNA extracted from cells grown on TDG, while the product was barely amplified from cells grown on succinate, thus indicating that the growth of A. xylosoxydans G5 on TDG led to increasing the expression of the iscS gene.

\section{2-D electrophoretic analysis}

Total protein extracts from the strains, obtained as described in section 'Materials and methods', were used 


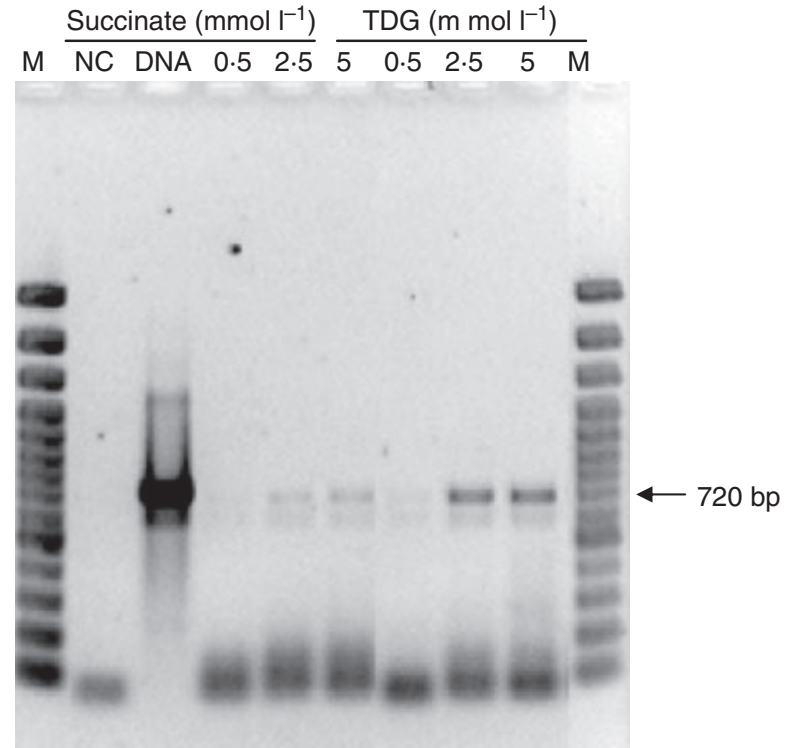

Figure 4 Transcriptional analysis of iscS gene for cysteine desulfurase of Achromobacter xylosoxydans G5. Total RNA from cells grown on succinate or on TDG was used as template for amplification. NC, negative control; DNA, positive control; M, O'Gene Ruler 1-kb ladder.

to generate two-dimensional isoelectric focusing-gel electrophoresis (2-D IEF/SDS-PAGE) maps (Fig. 5). Globally, a comparison of the maps of the strains grown on succinate or TDG evidenced several differences in the protein profiles. The map of TDG-grown G5 cells denotes a large increase in the amount of one spot around
$55 \mathrm{kDa}$ with pI 5.5 and two spots near $45 \mathrm{kDa}$ with pI between 7.5 and 8.5 . In regard to strain E4, the most important change in the maps concerns the spot of $70 \mathrm{kDa}$ with pI $5 \cdot 0$. This spot was excised from the gel, digested with trypsin and analysed by liquid chromatography electrospray ionization tandem mass spectrometry (LC-ESI-MS/MS), as described in section 'Materials and methods'. The protein was identified as a methanol dehydrogenase $[\mathrm{MDH}$ subunit 1 precursor from $P$. denitrificans (acc. no. P12293), with theoretical MW and pI of $69799 \mathrm{Da}$ and 5.08, respectively] with amino acid coverage of $19 \cdot 5 \%$ (eight peptides).

\section{Discussion}

The results presented here demonstrate that micro-organisms of different genera capable of TDG degradation may exist in contaminated sites. Previously, degradation studies of TDG have been mainly focussed on the catabolic pathway (Lee et al. 2000; Ermakova et al. 2002; Medvedeva et al. 2007) and up to now the genes and enzymes involved in TDG breakdown have not yet been characterized.

The initial breakdown of TDG can occur via three possible reactions: (i) oxidation of sulfur of TDG to DGSO and $\mathrm{DGSO}_{2}$, (ii) C-S bond cleavage yielding MeET and (iii) oxidation of the alcoholic groups.

DGSO and as a minor metabolite $\mathrm{DGSO}_{2}$, that can serve as a biological marker for sulfur mustard poisoning (Black and Read 1995), have been reported as

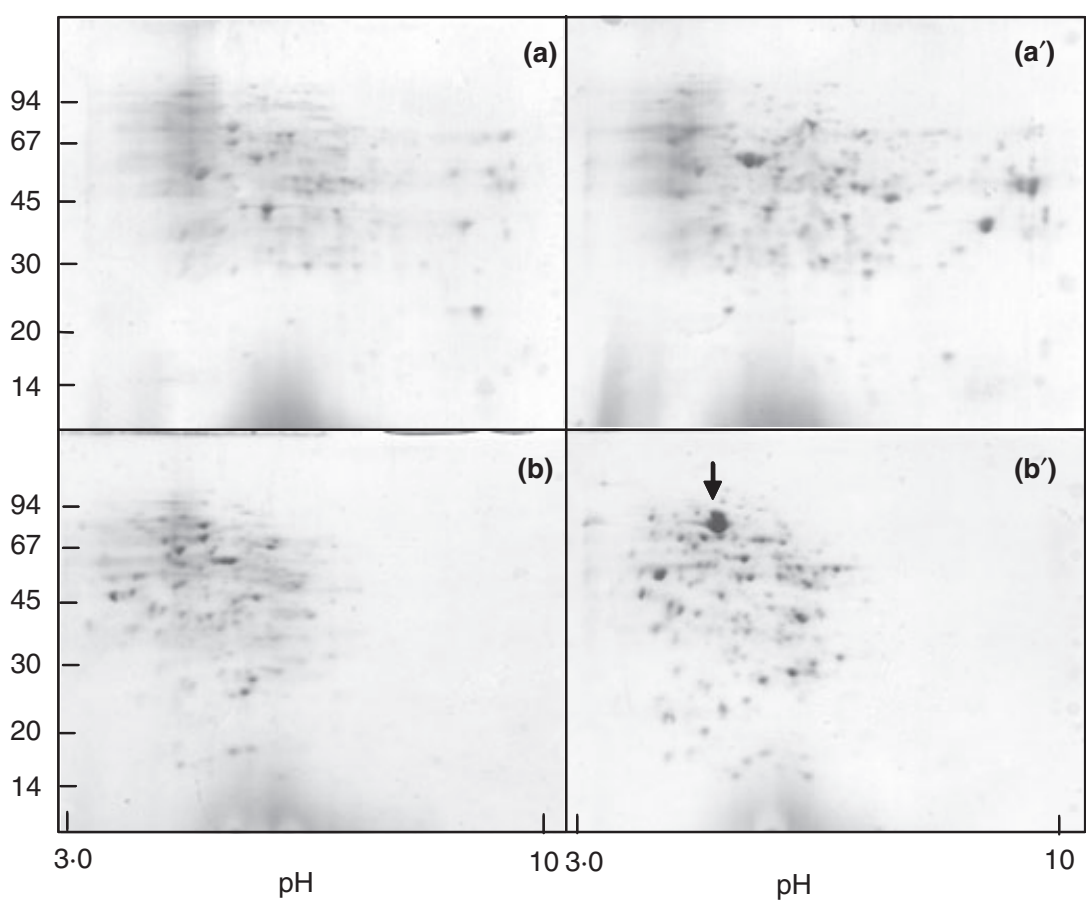

Figure 5 Coomassie blue-stained protein maps of strains: Achromobacter xylosoxydans G5 grown on succinate (a) and on TDG (a'); Paracoccus denitrificans E4 grown on succinate (b) and on TDG ( $\left.b^{\prime}\right)$. In panel $b^{\prime}$ the arrow shows the spot analysed by LC-ESI-MS/ MS. Experimental details are given in section 'Materials and methods'. 
in vivo metabolites of sulfur mustard in the urine of men and rats, providing evidence of the occurrence of oxidative processes other than the oxidation of the alcoholic group in TDG metabolism. Both the cytochromes, P450 and flavin monooxygenases, have been implicated in this type of transformation (Levi and Hodgson 1988).

DGSO and $\mathrm{DGSO}_{2}$ were never found to be formed by E4 and G5 cells growing on TDG. This result, together with the incapacity of the strains to grow on DGSO and $\mathrm{DGSO}_{2}$ led us to exclude that TDG degradation in these isolates occurred with the initial S oxidation. The C-S bond cleavage of TDG with the formation of MeET has been proposed by Medvedeva et al. (2007). Paracoccus denitrificans $\mathrm{E} 4$ and $A$. xylosoxydans G5 did not utilize MeET as carbon source to grow. These isolates attacked the TDG molecule by oxidizing both the primary alcohol groups to yield TDGA, according to Lee et al. (2000) and Ermakova et al. (2002). However, in P. denitrificans E4 cultures, the transient formation of small amounts of BHEDS, i.e. the oxidation product of MeET, was evidenced (Fig. 2). The transformation of MeET into BHEDS probably served E4 to preserve the MDH activity. This hypothesis can be supported by the results of Leono- vich et al. (2001) which found that MeET inhibited the alcohol oxidase activity of Pichia methanolica growing on different carbon sources, methanol included. BHEDS could be subsequently oxidized to bis-(mercaptoacetic acid) disulfide and then cleaved to MAA.

A butanol/thiodiglycol dehydrogenase was proposed to carry out the initial oxidation of TDG by Alc. xylosoxydans SH91 (Lee et al. 1997). The failure in the amplification of the $b d h A$ gene can exclude the involvement of such enzyme in G5 and E4 strains. Moreover, with regard to strain E4, the 2-D IEF/SDS-PAGE maps evidenced an important change of the spot of $70 \mathrm{kDa}$ with pI 5.0 of protein profiles (Fig. 5). This protein spot was identified as an MDH subunit 1 precursor by LC-ESI-MS/MS analysis, thus indicating that MDH oxidizes TDG to HETAL. The capability of $P$. denitrificans $\mathrm{E} 4$ to utilize methanol as carbon source strengthened this finding. 4-Methylpyrazole inhibited TDG oxidation in $P$. denitrificans E4 and partially in A. xylosoxydans G5, probably suggesting that different dehydrogenases may be responsible for TDG oxidation.

On the basis of the overall experimental results obtained with $P$. denitrificans E4, we suggest for TDG degradation the pathways shown in Fig. 6. According to

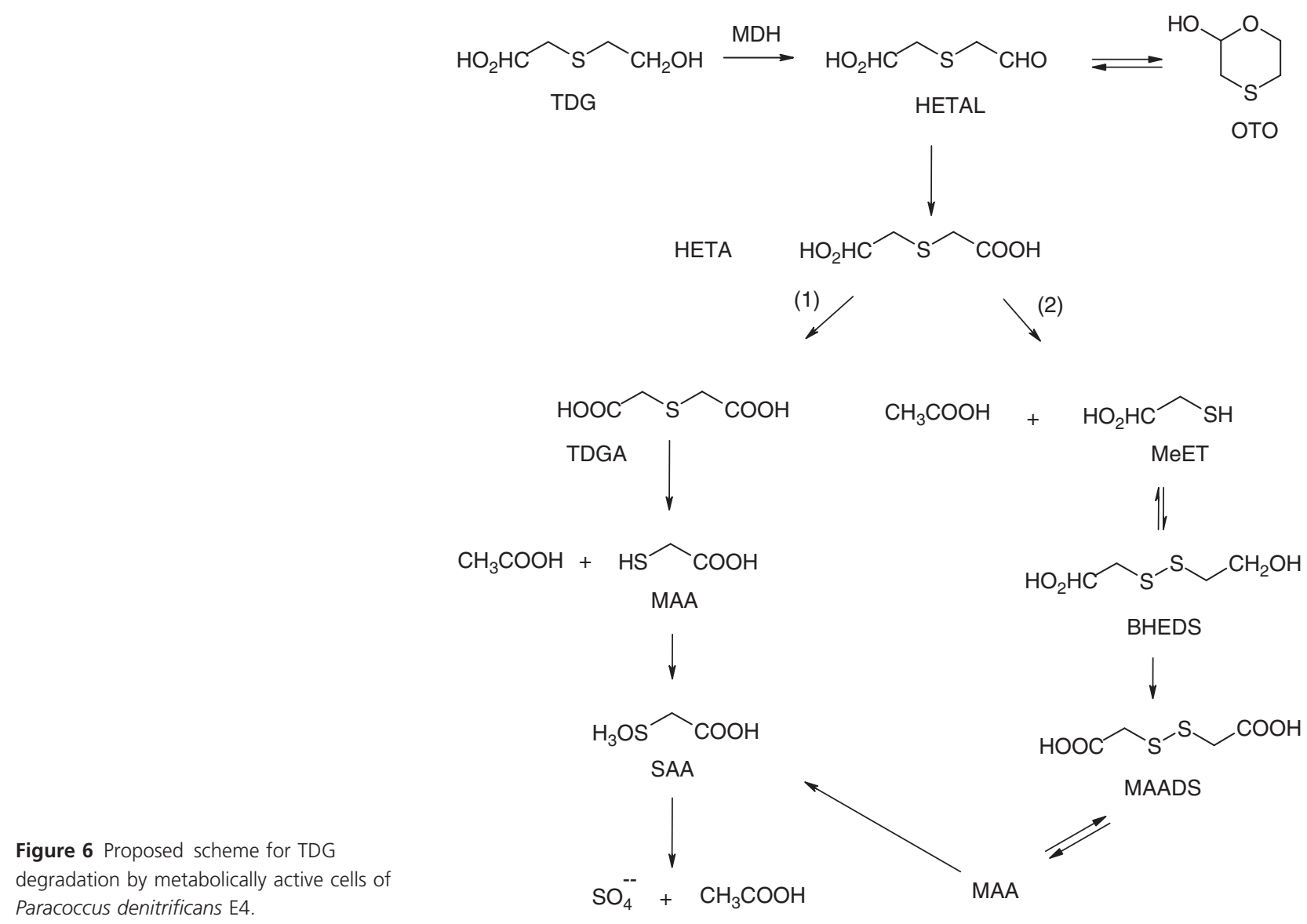


this scheme, TDG is oxidized to HETAL and then to HETA, whose subsequent oxidation can follow two routes. According to route 1, HETA is oxidized to TDGA with subsequent cleavage of the $\mathrm{C}-\mathrm{S}$ bond to form MAA and acetic acid. MAA is oxidized to SAA, and the second $\mathrm{C}-\mathrm{S}$ bond is cleaved forming acetate and sulfate. This pathway is in agreement with the growth characteristics and the identified metabolites. On the contrary, the presence of BHEDS in the culture broths allows us to consider that HETA, or even HETAL, can also be substrates for the enzymatic C-S bond cleavage. According to this possibility, in route 2 , which represents a minor pathway, the $\mathrm{C}-\mathrm{S}$ cleavage leads to the formation of acetic acid and MeET.

In G5, an iscS gene that encodes for cysteine desulfurase activity was amplified. Cysteine desulfurase is a pyridoxal-5'-phosphate (PLP)-dependent enzyme that catalyses the conversion of L-cysteine to L-alanine and sulfane sulfur, via the formation of an enzyme-bound persulfide intermediate. However, cysteine desulfurase is not directly involved in the $\mathrm{C}-\mathrm{S}$ cleavage of TDG because the enzyme requires substrates containing an amino group for binding PLP (Mihara and Esaki 2002). IscS-related genes have been found to play a role in the biosynthesis of NAD (Sun and Setlow 1993; Lauhon and Kambampati 2000) and in the mobilization of sulfur from cysteine to construct and repair $\mathrm{Fe}-\mathrm{S}$ clusters in protein substrates that, in turn, catalyse essential redox reactions in critical metabolic pathways (Lauhon and Kambampati 2000; Tantalean et al. 2003). A high NAD-requirement to oxidize the two TDG alcoholic groups might explain the higher expression level of the iscS gene in TDG-growing, rather than in succinategrowing, cells of A. xylosoxydans G5. Besides, alcohol dehydrogenase of some micro-organisms utilizes NAD as cofactor and as coenzyme (Arfman et al. 1997; Zachariou et al. 1986).

In conclusion, two new bacterial strains that successfully degraded TDG, the product of Yperite hydrolysis, have been described in this study. The strains can serve as powerful agents for the bioremediation of TDG-contaminated soils as well as for two-stage-tailored Yperite destruction processes. Furthermore, in bioaugmentation processes, growth and activity of $P$. denitrificans E4 and A. xylosoxydans G5 can be monitored by the detection of functional markers easily identifiable.

\section{Acknowledgements}

We wish to thank Drs Milena Colombo and Erica Tediosi for carrying out the enrichment cultures and HPLC analysis, and to Profs Marcello Duranti and Luca Espen for critical reading of the manuscript.

\section{References}

Arfman, N., Hektor, H.J., Bysrtrykh, V., Govorukhina, N.I., Dijkhuizen, L. and Frank, J. (1997) Properties of an $\mathrm{NAD}(\mathrm{H})$-containing methanol dehydrogenase and its activator protein from Bacillus methanolicus. Eur J Biochem 244, 426-433.

Black, R.M. and Read, R.W. (1995) Biological fate of sulphur mustard, 1,1'-thiobis(2-chloroethane): identification of $\beta$-lyase metabolites and hydrolysis products in human urine. Xenobiotica 25, 167-173.

Boronin, A.M., Ermakova, I.T., Sakharovsky, V.G., Grechkina, G.M., Starovoitov, I.I., Autenrieth, R.L. and Wild, J.R.

(2000) Ecologically safe destruction of the detoxification products of mustard-lewisite mixtures from the Russian chemical stockpile. J Chem Technol Biotechnol 75, 82-88.

Brimfield, A.A., Zweig, M.J., Novak, L.M. and Maxwell, D.M. (1998) In vitro oxidation of the hydrolysis product of sulphur mustard, 2,2'-thiobis-etahanol, by mammalian alcohol dehydrogenase. J Biochem Mol Toxicol 12, 361369.

Cavalca, L., Dell'Amico, E. and Andreoni, V. (2004) Intrinsic bioremediability of an aromatic hydrocarbon-polluted groundwater: diversity of bacterial population and toluene monoxygenase genes. Appl Microbiol Biotechnol 64, 576587.

Ermakova, I.T., Starovoitov, I.I., Tikhonova, E.B., Slepen'kin, A.V., Kashparov, K.I. and Boronin, A.M. (2002) Bioutilization of thiodiglycol, the product of mustard detoxification: isolation of degrading strains, study of biodegradation process and metabolic pathways. Process Biochem 38, 31-39.

Garcia-Ruiz, V., Martim-Lutero, L.E. and Puyet, A. (2002) Transformation of thiodiglycol by resting cells of Alcaligenes xylosoxydans PGH10. Biotechnol Prog 18, 252-256.

Harvey, S.P. and DeFrank, J.J. (1993) Biodegradation of chemical warfare agents: demilitarization applications. In Army Science: The New Frontiers, Military and Civilian Application ed. Kamely, D. and Sasmore, R. Woodlands: Bord Biomedical Services.

Harvey, S.P., Blades, T.A., Szafraniee, L.L., Beaudry, W.T., Haley, M.V., Rosso, T. and Young, G.P. (1998) Kinetic and toxicological parameters of mustard (HD) hydrolysis and biodegradation. In Arsenic and Old Mustard: Chemical Problems in the Destruction of Old arsenical and "Mustard" Munitions ed. Bunnet, J.F. and Mikolajczyk, M. pp. 115122 Dordrecht: Kluwer Academic.

Hur, H.G., Newman, L.M., Wackett, L.P. and Sadowsky, M.J. (1997) Toluene 2-monooxygenase-dependente growth of Burkholderia cepacia G4/PR1 on diethyl ether. Appl Environ Microbiol 63, 1606-1609.

Kawashima, H. (1995) Production of [(2-hydroxyethyl)thio] acetic acid from thiodiglycol (2,2'-thiodiethanol) by resting cell of Candida rugosa IFO1364. Biosci Biotechnol Biochem 59, 934-935. 
Kilbane, J.J. and Jakowski, K. (1996) Biocatalytic detoxification of 2-chloroethyl ethyl sulfide. J Chem Technol Biotechnol 65, 370-374.

Kim, J.-W., Rainina, E.I., Efremenko, E., Engler, C.R. and Wild, J.R. (1997) Degradation of thiodiglycol, the hydrolysis product of sulphur mustard, with bacteria immobilized within poly(vinyl)alcohol cryogels. Biotechnol Lett 19, 1067-1071.

Lauhon, C.T. and Kambampati, R. (2000) The iscS gene in Escherichia coli is required for the biosynthesis of 4-thiouridine, thiamine and NAD. J Biol Chem 275, 20096-20103.

Lee, T.S., Weigand, W.A. and Bentley, W.E. (1997) Observation of metabolite formation and variable yield in thiodiglycol biodegradation process: impact on reactor design. Appl Biochem Biotechnol 63-65, 743-757.

Lee, T.S., Chan, S.H., Weigand, W.A. and Bentley, W.E. (2000) Biocatalytic transformation of [(2-hydroxyethyl) thio] acetic acid and thiodiglycolic acid from thiodiglycol by Alcaligenes xylosoxydans ssp. xylosoxydans (SH91). Biotechnol Prog 16, 363-367.

Leonovich, S.A., Serkova, N.N. and Rabinovich, Y.M. (2001) Toxicity of mercaptoethanol to mutant strains of the yeast Pichia methanolica growing on different carbon sources. Appl Biochem Microbiol 37, 85-88.

Levi, P.E. and Hodgson, E. (1988) Stereospecificity in the oxidation of phorate and phorate sulfoxide by purified FAD-containing monooxygenase and cytochrome P-450 isozymes. Xenobiotica 18, 29-34.

Magni, C., Scarafoni, A., Herndl, A., Sessa, F., Prinsi, B. and Duranti, M. (2007) Combined 2D electrophoretic approaches for the study of white lupin mature seed storage proteome. Phytochemistry 68, 997-1007.
Medvedeva, N.G., Zaytceva, T., Polyak, Y. and Gridneva, J. (1998) The consumption of thiodiglycol by bacteria cultures Pseudomonas. Biotechnologiya 2, 89-92.

Medvedeva, N., Polyak, Y., Zaytseva, T. and Zinovieva, S. (2007) Soil bacterium Pseudomonas sp.: destroyer of mustard gas hydrolysis products. Biotechnol J 2, 1033 1039.

Mihara, H. and Esaki, N. (2002) Bacterial cysteine desulfurases: their function and mechanisms. Appl Microbiol Biotechnol 60, 12-23.

Munro, N.B., Talmage, S.S., Griffin, G.D., Waters, L.C., Watson, A.P., King, J.F. and Hauschild, V. (1999) The sources, fate, and toxicity of chemical warfare agent degradation products. Environ Health Perspect 107, 933-974.

Sun, D. and Setlow, P. (1993) Cloning, nucleotide sequence, and regulation of the Bacillus subtilis $\operatorname{nadB}$ gene and a nifS-like gene, both of which are essential for NAD biosynthesis. J Bacteriol 175, 1423-1432.

Tantalean, J.C., Araya, M.A., Saavedra, C.P., Fuentes, D.E., Perez, J.M., Calderon, I.L., Youderian, P. and Vasquez, C.C. (2003) The Geobacillus stearothermophilus V iscS gene, encoding cysteine desulfurase, confers resistance to potassium tellurite in Escherichia coli K-12. J Bacteriol 185, 5831-5837.

Weisburg, W.G., Barns, S.M., Pelletier, D.A. and Lane, D.J. (1991) 16S ribosomal DNA for phylogenetic study. J Bacteriol 173, 697-703.

Zachariou, M. and Scopes, R.K. (1986) Glucose-fructose oxidoreductase, a new enzyme isolated from Zymomonas mobilis that is responsible for sorbitol production. J Bacteriol 167, 863-869. 